\title{
Comparative Study of Antibacterial and Haemolytic Activities in Sea Bass, European Eel and Blackspot Seabream
}

\author{
Gabriella Caruso ${ }^{1, *}$, Giulia Maricchiolo ${ }^{1}$, Lucrezia Genovese ${ }^{1}$, Francesca De Pasquale ${ }^{1}$, Rosalba \\ Caruso $^{2}$, Maria Gabriella Denaro ${ }^{3}$, Santi Delia ${ }^{4}$ and Pasqualina Laganà ${ }^{4}$ \\ ${ }^{I}$ National Research Council, Institute for Coastal Marine Environment (IAMC-CNR), Messina, Italy \\ ${ }^{2}$ Hospital Agency “G. Martino”, U.O. Tissue Typing, Messina, Italy \\ ${ }^{3}$ Department of Biological and Environmental Sciences, University of Messina, Messina, Italy \\ ${ }^{4}$ Department of Biomedical Sciences and Morphological and Functional Images, University of Messina, Messina, Italy
}

\begin{abstract}
Sea bass (Dicentrarchus labrax, Moronidae), European eel (Anguilla anguilla, Anguillidae) and blackspot seabream (Pagellus bogaraveo, Sparidae) were studied to check their mucus, blood sera and tissue samples for antibacterial and agglutinating activity against a variety of Gram negative and positive bacteria. Samples were also examined for their haemolytic properties against sheep red blood cells.
\end{abstract}

The highest antibacterial activity was detected in the blood sera of blackspot seabream and European eel (against Vibrio alginolyticus) and in the kidneys of sea bass (against Photobacterium damselae subsp. piscicida). Haemolytic properties against sheep red blood cells were observed in the mucus of sea bass and blackspot seabream, as well as in the sera of eel and sea bass. The sera of sea bass and eel showed also agglutinating activity against Pseudomonas aeruginosa and Staphylococcus aureus; the mucus of sea bass was able to agglutinate isolates of Vibrio fluvialis, V. alginolyticus and A. hydrophila.

The study suggested that the mucus secretions, biological fluids and organs of the examined fish species can be regarded as an interesting source of bioactive compounds with antibacterial and haemolytic properties.

Keywords: Antibacterial properties, disease resistance, haemolytic activity, mucus, serum, Teleosts, tissues.

\section{INTRODUCTION}

Like other organisms living in aquatic environments, fish possess complex defense mechanisms to protect them from a wide range of pathogenic and non-pathogenic microorganisms. The immune system of fish is physiologically similar to that of higher vertebrates, although the main difference is that fish are free-living organisms already from early embryonic stages of life and depend on their innate immune system for survival, in contrast to higher vertebrates [1]. Key innate immune components of fish include the mucus layer on the skin, gills and gastrointestinal tract, and constituents of the blood such as phagocytes and natural killer cells. Particularly, skin mucus and gills are recognised as the first physical barriers to infections [2-4]. The mucus layer, which covers the fish surface and is secreted by the goblet or mucus cells in the epidermis, plays an important role against the skin colonization by bacteria, fungi and parasites. It represents not only a physical but also a biochemical barrier between fish and its aquatic

*Address correspondence to this author at the National Research Council, Institute for Coastal Marine Environment, Spianata S. Raineri, 86 - 98122 Messina, Italy; Tel: +39 090 6015423; Fax: +39 090669007 ;

E-mail: gabriella.caruso@iamc.cnr.it environment, since it contains a variety of biologically active substances involved in fish innate immunity such as lysozyme, lectins, immunoglobulins, C-reactive protein, apolipoprotein A-I and antimicrobial peptides which protect fish from potential pathogens $[2,5,6]$. The mucosal barrier of the skin is an extremely important barrier to diseases, being fish constantly immersed in media containing potentially harmful agents [5].

The study of the mechanisms involved in the natural defence of fish against bacterial pathogens is of particular significance for fish welfare, since a direct relationship between the fish ability to counteract diseases (i.e. through own antibacterial properties) and health status has been established [7, 8]. So, the characterization of the antibacterial defense systems in these organisms is required in order to get insights on the complex mechanisms that regulate immunity and diseases. Previous studies have documented that secretions and tissues of Teleost fish possess antibacterial properties towards Gram-negative and positive microorganisms [9-11], and haemolytic properties [2]; nevertheless, the little availability of comparative studies on different species in the pertinent literature makes this subject a topic of growing interest. Moreover, search for natural antibacterial agents, able to control infectious diseases, is gaining importance in recent years [12], in relation to the 
widespread occurrence of antibiotic resistance phenomena [13]. In this context, a study has undertaken on samples of mucus, blood serum and organs (kidney and spleen) of three Teleost species (sea bass, Dicentrarchus labrax Linnaeus), European eel (Anguilla anguilla Linnaeus) and blackspot seabream (Pagellus bogaraveo Brünnich), to explore the occurrence of antibacterial properties against some potentially pathogenic bacteria. Moreover, blood sera of the same species were also examined for the possible lytic capacity against sheep red blood cells, to better characterize the non-specific immune defense abilities of such Teleosts, which are still little known.

The selection of the three different fish species examined in the present study was performed according to the following criteria: sea bass is the most common species reared in Mediterranean aquaculture, European eel represents an important economic resource for Italian fish farming, being the most common cultured fish after trout and carp, whereas blackspot seabream is considered as a candidate species for Mediterranean aquaculture diversification [14].

\section{MATERIALS AND METHODOLOGY}

\subsection{Fish Specimens}

The individuals of sea bass, European eel and blackspot seabream examined during the present study were obtained from a commercial Sicilian fish farm and reared at the Experimental Aquaculture Plant of the CNR-IAMC, Messina, Italy. Throughout the experimental period, fish were fed a commercial dry diet for carnivorous fish (Trouvit pellets, TROUW NUTRITION SpA, Verona, Italy), administered until satiation. Each tank was supplied with a constant aerated flow of seawater. The water temperature was $24-25^{\circ} \mathrm{C}$, pH was 8.2 and dissolved oxygen was 7-8 mg $\mathrm{L}^{-1}$. Photoperiod was kept natural.

\subsection{Collection and Treatment of the Biological Samples}

Before sampling, fish were anesthetized and euthanized with a lethal dose of MS-222 (tricaine methanesulfonate, $0.1 \mathrm{~g} \mathrm{~L}^{-1}$, Sigma-Aldrich, Milan, Italy). Samples of skin mucus, blood serum, kidney and spleen were collected from three individuals of each species under study. Mucus was collected from each fish by gently scraping with a sterile spatula from the dorsal surface of the body, avoiding the ventral side to avoid intestinal and sperm contamination. It was stored in sterile Eppendorf microcentrifuge tubes and mixed with an equal amount of sterilized physiological saline $(0.85 \% \mathrm{NaCl})$. Precipitates present in the suspension were removed by centrifugation at $6000 \mathrm{x} \mathrm{g}$ and the supernatant was collected and stored at $-20^{\circ} \mathrm{C}$ until analysis.

Blood samples were drawn separately from the caudal vein of each individual; small volumes were collected in heparinised (14 International Units $\left.\mathrm{mL}^{-1}\right)$ tubes and centrifuged; the obtained plasma was stored at $-80^{\circ} \mathrm{C}$ for further antibacterial activity assay.

From each fish, spleen and kidney samples were also removed using a sterile scalpel, homogenized in physiological saline $(1: 10, \mathrm{w} / \mathrm{v})$ and stored at $-80^{\circ} \mathrm{C}$ until analysis. From each fish, amounts of $0.5 \mathrm{~mL}$ of mucus and blood sera were collected, whereas for spleen and kidney the quantity removed from each fish was 50 milligrams.

All the methodologies applied in this study were standardized to make the comparisons among different fish and organs feasible and reproducible.

\subsection{Antibacterial Activity Measurements}

Antibacterial activity of mucus and blood sera was determined against a collection of target strains of human pathogens and environmental bacteria. The target bacterial strains used in this study belonged to a collection of the Department of Biomedical Sciences and Morphological and Function Images (Prof. Delia, Dr. Laganà, University of Messina, Italy). Strains of Gram-negative (Escherichia coli, Klebsiella pneumoniae, Pseudomonas aeruginosa, Salmonella typhi, Vibrio fluvialis, $V$. alginolyticus, $V$. anguillarum- strains 975 and 953, V. parahaemolyticus) and Gram-positive bacteria (Enterococcus faecium, Staphylococcus aureus, Staphylococcus epidermidis) as well as some fish pathogens were considered (Aeromonas hydrophila, Photobacterium damselae subsp. piscicida).

The antibacterial activity was measured using the standard disc diffusion method, according to the procedure indicated by Bauer et al. [15], with some modifications. All isolates were cultured in Brain Heart Infusion broth (Oxoid, Rodano, Milan, Italy), adjusted to correspond to a final concentration of $10^{8}$ cell $\mathrm{mL}^{-1}$ with a standard of McFarland density. Plates of Tryptic Soy agar (Oxoid) added with 1\% $\mathrm{NaCl}$ were inoculated with $50 \mu \mathrm{L}$ of each broth culture by spreading the agar surface using a sterile cotton swab. Sterile discs of absorbent paper (diameter: $6 \mathrm{~mm}$ ) were imbibed with $20 \mu \mathrm{L}$ of each sample or homogenate and then placed on the surface of each plate with the help of a sterilized forceps. Sterile water was used as the control for the antibacterial activity assays, showing no inhibition of bacterial growth. After incubation at 22 or $35{ }^{\circ} \mathrm{C}$ for $24 \mathrm{~h}$ (depending on the optimal temperature for each bacterial species), the diameters of the zones of inhibition of bacterial growth were measured, considering the edges of the clear zone, using a precision calliper (Mitutoyo, Andover, UK).

\subsection{Haemolytic activity Assay}

The haemolytic activity of blood sera and mucus was measured on Columbia Blood agar base (Oxoid) plates added with 5\% sheep red blood cells (Microbiol s.n.c., Macchiareddu, Cagliari, Italy) and incubated at $30^{\circ} \mathrm{C}$ for 24 $\mathrm{h}$. The diameter of haemolysis produced after incubation was measured using a precision ruler.

\subsection{Agglutinating Activity Assay}

The agglutinating activity of serum and mucus samples was assayed by mixing some drops of each sample with each broth culture on the surface of a glass slide. The appearance, after some seconds of gentle manual agitation of the slide, of aggregates of bacterial cells was considered as a positive result. 
Table 1. Antibacterial activity of samples of mucus, blood sera and tissues homogenates from European eel, blackspot seabream and sea bass.

The mean diameters of inhibition \pm standard deviation (in $\mathrm{cm}$ ) measured on plates of Tryptic Soy Agar added with $1.5 \%$ $\mathrm{NaCl}$ are reported.

\begin{tabular}{|c|c|c|c|c|c|}
\hline MUCUS & $V$ & $V$ & $V$ & S. aureus & Ps. \\
\hline & fluvialis & alginolyticus & parahaemolyticus & & aeruginosa \\
\hline eel & $0.80 \pm 0.30$ & $0.80 \pm 0.20$ & $0.80 \pm 0.30$ & $0.80 \pm 0.20$ & / \\
\hline sea bream & l & l & $0.80 \pm 0.25$ & l & l \\
\hline sea bass & $0.80 \pm 0.20$ & $0.80 \pm 0.35$ & $0.87 \pm 0.30$ & $0.80 \pm 0.25$ & $0.80 \pm 0.25$ \\
\hline \multirow[t]{2}{*}{ BLOOD SERA } & V. anguillarum & V. anguillarum & $V$ & $V$. & Ps. \\
\hline & (strain 975) & (strain 953) & alginolyticus & parahaem. & aeruginosa \\
\hline eel & I & l & $0.95 \pm 0.20$ & I & $0.90 \pm 0.40$ \\
\hline sea bream & $0.80 \pm 0.20$ & I & $1.50 \pm 0.50$ & $1.00 \pm 0.30$ & I \\
\hline sea bass & l & $0.80 \pm 0.25$ & $0.87 \pm 0.25$ & l & l \\
\hline \multirow[t]{2}{*}{ TISSUES } & P. damselae & E. coli & $V$ & Ps. & \\
\hline & & & alginolyticus & aeruginosa & \\
\hline eel - kidney & $0.90 \pm 0.50$ & $0.75 \pm 0.20$ & I & $0.85 \pm 0.35$ & \\
\hline eel - spleen & l & $0.65 \pm 0.20$ & I & $0.90 \pm 0.40$ & \\
\hline sea bream - kidney & l & $0.75 \pm 0.20$ & $0.90 \pm 0.40$ & $0.70 \pm 0.20$ & \\
\hline sea bass - kidney & $1.13 \pm 0.40$ & I & $0.77 \pm 0.25$ & $0.93 \pm 0.40$ & \\
\hline$/$, no reaction & & & & & \\
\hline
\end{tabular}

\subsection{Statistical Analysis}

Results were reported as the mean value \pm standard deviation obtained from three individuals for each species. Each assay was repeated three times to assess the reproducibility of the results. Normality of the data was previously assessed using a Shapiro Wilk test and homogeneity of variance was also verified using the Levene test. Non-normally distributed data were log-transformed prior to analysis. Statistical differences among the obtained data were assessed by One way Analysis of Variance (ANOVA), according to the Fisher's method [16]. Only the $\mathrm{P}$ values $<0.05$ were considered as statistically significant. The software Sigma Stat version 3.0 was used for the analysis.

\section{RESULTS}

\subsection{Antibacterial Activity Measurements}

The results of the antibacterial activity assays performed on the samples of mucus, blood sera and tissues homogenates are reported in Table 1 . To compare the antibacterial activity of the various samples across the species, all the samples were tested against the same bacteria. For convenience, only the positive results are shown in the Table.

Regarding the samples of mucus, both in eel and sea bass a broad spectrum of antibacterial activity against $V$. fluvialis, $V$. parahaemolyticus and $V$. alginolyticus was recorded. The two fish species showed similar levels of activity against $V$. fluvialis and $V$. alginolyticus, as also confirmed by the ANOVA results (Table 2 ). In sea bass, the activity of mucus against $V$. parahaemolyticus did not differ significantly from that of eel. S. aureus was similarly sensitive to the mucus of sea bass and eel. The mucus of blackspot seabream showed antibacterial activity against $V$. parahaemolyticus comparable to that of eel.

Blackspot seabream sera showed a strong antibacterial activity against $V$. alginolyticus and $V$. parahaemolyticus; the activity against $V$. alginolyticus was not significantly different from those measured in both eel and sea bass sera. 
Table 2. Results of Analysis of Variance (ANOVA) performed among species and among samples. The Probability values of the comparisons between groups are reported; asterisks indicate statistically significant differences. n.d.= not determined.

\begin{tabular}{|c|c|c|c|c|}
\hline ANOVA AMONG SPECIES & & & & \\
\hline \multicolumn{5}{|l|}{ MUCUS } \\
\hline & V.fluvialis & V. alginol. & V.parahaemol. & S. aureus \\
\hline eel/sea bass & 0.774 & 0.542 & 0.749 & 0.715 \\
\hline eel/seabream & & & 0.976 & \\
\hline seabream/sea bass & & & 0.728 & \\
\hline \multirow[t]{2}{*}{ BLOOD SERA } & & & & \\
\hline & & V. alginol. & & \\
\hline eel/sea bass & & 0.687 & & \\
\hline eel/seabream & & 0.152 & & \\
\hline seabream/sea bass & & 0.123 & & \\
\hline \multicolumn{5}{|l|}{ TISSUES } \\
\hline & P.damselae & E. coli & V. alginol. & Ps. aerugin. \\
\hline eel kidney/eel spleen & & 0.573 & & 0.878 \\
\hline eel kidney/seabream kidney & & n.d. & & 0.554 \\
\hline eel kidney/sea bass kidney & 0.568 & & & 0.807 \\
\hline \multicolumn{2}{|c|}{ seabream kidney/sea bass kidney } & & 0.658 & 0.423 \\
\hline eel spleen/seabream kidney & & 0.573 & & 0.482 \\
\hline eel spleen/sea bass kidney & & & & 0.931 \\
\hline \multicolumn{5}{|l|}{ ANOVA AMONG SAMPLES } \\
\hline \multirow[t]{2}{*}{ Eel } & & & & \\
\hline & V. alginolyticus & & & \\
\hline \multirow[t]{2}{*}{ mucus $v s$. sera } & 0.410 & & & \\
\hline & Ps. aeruginosa & & & \\
\hline sera $v s$. kidney & 0.878 & & & \\
\hline sera $v s$. spleen & n.d. & & & \\
\hline kidney $v s$. spleen & 0.878 & & & \\
\hline
\end{tabular}


Table 2. contd...

\begin{tabular}{|c|c|c|c|c|}
\hline \multicolumn{5}{|c|}{ ANOVA AMONG SAMPLES } \\
\hline & V.fluvialis & V. alginol. & V.parahaemol. & S. aureus \\
\hline \multicolumn{5}{|l|}{ Seabream } \\
\hline & V. parahaemolyticus & & & \\
\hline mucus vs sera & 0.425 & & & \\
\hline \multicolumn{2}{|l|}{ Sea bass } & & & \\
\hline & V. alginolyticus & & & \\
\hline \multirow[t]{2}{*}{ mucus vs kidney } & 0.910 & & & \\
\hline & Ps. aeruginosa & & & \\
\hline mucus vs kidney & 0.658 & & & \\
\hline
\end{tabular}

Eel sera also exhibited high antibacterial activity against $P s$. aeruginosa. Also sea bass sera possessed antibacterial activity against $V$. alginolyticus.

None of the examined sera showed antibacterial activity against bacterial strains of human origin, both Gramnegative (E. coli, K. pneumoniae) and positive (E. faecium, $S$. aureus) tested in this study(data not shown in Table $\mathbf{1}$ ).

Considering the homogenates of kidney samples, a great antibacterial activity was recorded for the kidney of sea bass against $P$. damselae subsp. piscicida, Ps. aeruginosa and $V$. alginolyticus (Table 1). Also the kidney of eel showed good levels of antibacterial activity against $P$. damselae subsp. piscicida and Ps. aeruginosa, being weakly active against E. coli too. The spleen of eel exhibited a good antibacterial activity against $P$ s. aeruginosa and only a weak activity against $E$. coli. The kidney of blackspot seabream showed antibacterial activity against $V$. alginolyticus, E. coli and $P$ s. aeruginosa, but the measured values did not differ significantly from those of sea bass kidney and eel spleen (Table 2).

\subsection{Haemolytic Activity Assay}

The results of the haemolytic activity assay performed on mucus and blood sera are shown in Table 3. Positive results

Table 3. Haemolytic properties of mucus and blood sera. The mean diameters of lysis \pm standard deviation (in cm) obtained on Columbia agar plates added with $5 \%$ sheep blood red cells are reported.

\begin{tabular}{|c|c|}
\hline A. anguilla - serum & $1.35 \pm 0.40$ \\
\hline D. labrax - serum & $1.30 \pm 0.30$ \\
\hline D. labrax - mucus & $1.00 \pm 0.30$ \\
\hline P. bogaraveo - mucus & $0.80 \pm 0.20$ \\
\hline
\end{tabular}

against sheep red blood cells were found for the sera of sea bass and eel; a weak hemolytic activity was also observed for the mucus of sea bass and blackspot seabream. No significant differences were found comparing the halos of haemolysis yielded by the mucus of blackspot seabream (showing the lowest diameter) with those produced by the sera of sea bass and eel (showing the highest ones) $(\mathrm{F}=5.769, \mathrm{P}=0.074$ and $4.537, \mathrm{P}=0.10$, respectively $)$.

\subsection{Agglutinating Activity Assay}

The agglutinating activity assayed on mucus and blood sera samples yielded the results summarized in Table 4. The sera of sea bass and eel showed an agglutinating ability against Ps. aeruginosa and $S$. aureus, while none of them was able to agglutinate different species of Vibrio (V. fluvialis, V. alginolyticus, V. anguillarum, V. parahaemolyticus) or A. hydrophila. A good agglutinating ability was also recorded for the mucus of sea bass, against V. fluvialis, V. alginolyticus and A. hydrophila.

\section{DISCUSSION}

The bacteria used for the present study have been selected because these microorganisms are likely to be spread in the habitat where the examined fishes live. The results obtained in the present study indicate that fish mucus, sera and kidneys from sea bass, blackspot seabream, and European eel possess both antibacterial and haemolytic properties and therefore they could be regarded as an interesting source of active biocompounds. The antibacterial activity is expressed above all against some Gram-negative bacterial strains widespread in aquatic environments (Vibrio spp., A. hydrophila, Ps. aeruginosa, P. damselae subsp. piscicida), while it is weak or absent against other strains of marine (V. anguillarum) or human origin (E. coli, E. faecium, K. pneumoniae, with the exception of S. aureus). The highest antibacterial properties are observed in blackspot 
Table 4. Agglutinating properties of mucus and blood sera against the target bacteria.

\begin{tabular}{|c|c|c|c|}
\hline Bacterial Strains & & & \\
\hline & A. anguilla - serum & D. labrax - serum & D. labrax - mucus \\
\hline \hline Proteus mirabilis & - & - & - \\
\hline Vibrio fluvialis & - & - & + \\
\hline Vibrio alginolyticus & - & - & + \\
\hline Vibrio anguillarum & - & - & - \\
\hline Vibrio parahaemolyticus & - & - & - \\
\hline Aeromonas hydrophila & - & + & + \\
\hline Pseudomonas aeruginosa & + & + & - \\
\hline Staphylococcus aureus & - & $(+)$ & - \\
\hline Escherichia coli & - & - & - \\
\hline Klebsiella pneumoniae & - & - & + \\
\hline
\end{tabular}

+ , positive reaction; $(+)$, weak positive reaction; -, negative reaction

seabream sera against $V$. alginolyticus and in sea bass kidney against $P$. damselae subsp. piscicida. The detection of antibacterial activity in the skin secretions and organs of the examined species underline their role in the mechanisms of innate immune defense, as known for other fish species [1719]. On the other hand, the antimicrobial properties of skin secretions of many fish species are widely known. Several studies have previously demonstrated the antimicrobial property of epidermal mucus in common carp, Cyprinus carpio [20]; queen parrot fish, Scarus vetula [21]; hagfish, Myxine glutinosa [22]; catfish, Arius maculatus [23]. Antibacterial activity against $S$. typhi, K. pneumoniae, $S$. aureus, E. coli, V. cholerae was shown by the epidermal mucus secretion of marine stingrays (Dasyatis sephen and Himantura gerrardi) [24]. The mucus and epidermal extract of Tinfoil barb fish were able to inhibit the growth of Bacillus cereus, S. aureus, Shigella boydii and E. coli [25]. Bioactive molecules (lysozyme, alkaline phosphatase and proteases, esterase, peroxidase) are constitutively present in both skin mucus and serum of gilthead seabream, Sparus aurata [19].

In European eel, the presence of antibacterial and haemolytic activity has been previously documented in the mucus [26]; particularly, positive reactions against $P S$. aeruginosa, V. parahaemolyticus, E. coli, S. aureus, S. typhi, S. paratyphi, K. pneumoniae, K. oxytoca, Proteus mirabilis and Lactobacillus vulgaris were reported. In the present study, the eel mucus was found active against $V$. parahaemolyticus, $V$. fluvialis, $V$. alginolyticus and $S$. aureus; compared to mucus, higher antibacterial activity against $P$ s. aeruginosa and $V$. alginolyticus was recorded in eel sera.

In addition, the mucus of sea bass and blackspot seabream, together with the sera of eel and sea bass examined in this study, show haemolytic properties. Also Bragadeeswaran et al. [27] found that the mucus of two fish species (Cynoglossus arel and Arius caelatus) has not only high antimicrobial activity against human pathogens ( $V$. cholerae, V. parahaemolyticus, S. aureus) but also high haemolytic activity. A similar result was reported in the mucus of two other fish species, Channa punctatus and Cirrhinus mrigala [28]. Also Uthayakumar et al. [29] observed that the mucus secretion of Mastacembelus armatus possesses a potent haemolytic activity against sheep and cow blood cells. Previously, Hellio et al. [30] reported in the mucus of bony fishes the presence of some antimicrobial agents which bind with microbes and destroy the blood cells, resulting in haemolysis. It has to be noted, however, that although antibacterial compounds have been found in many fish species, it is difficult to perform quantitative comparisons among several studies, since the expression of antibacterial proteins may be affected by a different solubility in the aqueous or acidic medium of extraction. Significant variations in the relative levels of epidermal mucus enzymes involved in the innate immune system of different fish species (i.e. lysozyme, cathepsin B, proteases and alkaline phosphatase) were also reported [11], although it is still unclear whether they could depend on evolutionary or genetic adaptation of the organisms to environmental factors. Also the response of haemolytic reactions may differ considerably depending on the used erythrocytes (i.e. sheep, chicken or goat).

Comparing the samples tested for antibacterial properties in this study, mucus, blood sera and kidney of sea bass exhibit antibacterial activity against $V$. alginolyticus. However, no significant differences among the diameters of inhibition were observed. In blackspot seabream, both kidney and blood sera show antibacterial activity against this same bacterium. Similar levels of antibacterial activity against Ps. aeruginosa are found in eel spleen and blood sera. In gilthead seabream, skin mucus is reported to have a stronger bactericidal activity than serum against fish pathogens [19].

Another interesting result obtained in the present study is the detection in sea bass mucus of agglutinating activity against $V$. fluvialis, $V$. alginolyticus and $A$. hydrophila, being all these microorganisms widely distributed in marine and 
brackish environments, this finding led us to hypothesize that sea bass could be less susceptible than eel and blackspot seabream to infectious diseases (i.e. vibriosis) sustained by these bacteria.

\section{CONCLUSION}

The detection of antibacterial and haemolytic properties in the biological secretions and tissues of the examined fish species stresses the need for their further characterization. Further efforts are necessary for the chemical purification and isolation of active antimicrobial compounds. Extraction of antimicrobial peptides could provide not only a good and sustainable way for the utilization of fish by-products like mucus and skin, but it could also contribute in advancing current understanding of the function of these substances in the mucosal defense mechanisms of fish, in order to establish their possible applications as natural therapeutic compounds against infectious diseases.

\section{CONFLICT OF INTEREST}

The authors confirm that this article content has no conflict of interest.

\section{ACKNOWLEDGEMENTS}

Declared none.

\section{REFERENCES}

[1] Uribe C, Folch H, Enriquez R, Moran G. Innate and adaptive immunity in teleost fish: a review. Vet Med Czech 2011; 56(10): 486-503.

[2] Ingram GA. Substances involved in the natural resistance of fish to infection: a review. J Fish Biol 1980; 16: 23-60.

[3] Shephard KL. Functions for fish mucus. Rev Fish Biol Fish 1994; 4: 401-29.

[4] Ellis AE. Innate host defence mechanism of fish against viruses and bacteria. Dev Comp Immunol 2001; 25: 827-39.

[5] Magnadottir B. Immunological control of fish diseases. J Mar Biotechnol 2010; 12: 361-79.

[6] Saurabh S, Sahoo PK. Lysozyme: an important defence molecule of fish innate immune system. Aquacult Res 2008; 39: 223-39.

[7] Parkhurst NW, Van der Kraak G. In: Iwama GK, Pickering AD, Sumpter JP, Schreck CB, Eds. Fish stress and Health in Aquaculture. UK. Cambridge University Press 1997; pp. 73-93.

[8] Iwama G, Pickering A, Sumpter J, Schreck C, Eds. Fish Stress and Health in Aquaculture. Cambridge University Press 1997; pp. 1290.

[9] Ebran N, Julien S, Orange N, Saglio P, Lemaitre C, Molle G. Pore forming properties and antibacterial activity of proteins extracted from epidermal mucus of fish. Comp Biochem Physiol 1999; 122: 181-9.

[10] Hellio C, Pons AM, Beaupoil C, Bourgougnon N, Le Gal Y. Antibacterial, antifungal and cytotoxic activities of extracts from fish epidermis and epidermal mucus. Int. J. Antimicrob. Agents 2002; 20: 214-9.

[11] Subramanian S, MacKinnon SL, Ross NW. A comparative study on innate immune parameters in the epidermal mucus of various fish species. Comp Biochem Physiol Part B 2007; 148: 256-63.
[12] Kumari U, Nigam A-K, Mittal S, Mittal AK. Antibacterial properties of the skin mucus of the freshwater fishes, Rita rita and Channa punctatus. Eur Rev Med Pharmacol Sci 2011; 15: 781-6.

[13] Laganà P, Caruso G, Minutoli E, Zaccone R, Delia S. Susceptibility to antibiotics of Vibrio spp. and Photobacterium damsela ssp. piscicida strains isolated from Italian aquaculture farms. New Microbiol 2011; 34(1): 53-63.

[14] Caruso G, Denaro MG, Genovese L. Digestive enzymes in some Teleost species of interest for Mediterranean aquaculture. The Open Fish Sci J 2009, 2: 74-86.

[15] Bauer AW, Kirby WMM, Sherris JC, Turck M. Antibiotic susceptibility testing by a standardized single disc method. Am J Clin Pathol 1996; 45: 493-496.

[16] Lison L. Statistica applicata alla biologia sperimentale: la programmazione dell'esperimento e l'analisi dei risultati. CEA 1986; pp. 1-381.

[17] Ellis AE. Immunity to bacteria in fish. Fish Shellfish Immunol 1999; 9: 291-308.

[18] Esteban MA. An overview of the immunological defenses in fish skin. ISRN Immunology 2012; Article ID853470, 1-29, doi:10.5402/2012/853470.

[19] Guardiola FA, Cuesta A, Arizcun M, Meseguer J, Esteban MA. Comparative skin mucus and serum humoral defence mechanisms in the teleost gilthead seabream (Sparus aurata). Fish Shellfish Immunol 2014; 36: 545-51.

[20] Lemaitre C, Orange N, Saglio P, Saint N, Gagnon T, Molle G. Characterization and ion channel activities of novel antimicrobial proteins from the skin mucosa of carp (Cyprinus carpio). Eur J Biochem 1996; 240: 143-9.

[21] Videler H, Geertjes GJ, Videler JJ. Biochemical characteristics and antibiotic properties of the mucous envelope of the queen parrot fish. J Fish Biol 1999; 54: 1124-7.

[22] Subramanian S, Ross NW, Shawna L, Myxinidin M. A novel antimicrobial peptide from the epidermal mucus of hagfish. L. Mar Biotechnol 2009; 11: 748-75.

[23] Manivasagan P, Annamalai N, Ashokkumar S, Sampathkumar P. Studies on the proteinaceous gel secretion from the skin of the catfish, Arius maculatus (Thunberg, 1792). Afr J Biotechnol 2009; 8(24): 7125-9.

[24] Vennila R, Kumar KR, Kanchana S, Arumugam M, Vijayalakshmi S, Balasubramaniam T. Preliminary investigation on antimicrobial and proteolytic property of the epidermal mucus secretion of marine stingrays. Asian Pac J Trop Biomed 2011; 1(2) S239-43.

[25] Subhashini S, Lavanya J, Jain S, Agihotri T. Screening of antibacterial and cytotoxic activity of extracts from epidermis and epidermal mucus of Barbonymus schwanenfeldii (Tinfoil barb fish). Int J Res Engin Technol 2013; 2(4): 492-7.

[26] Bragadeeswaran S, Thangaraj S. Hemolytic and antibacterial studies on skin mucus of eel fish, Anguilla anguilla Linnaeus, 1758. Asian J Biol Sci 2011; 4(3): 272-6.

[27] Bragadeeswaran S, Priyadharshini S, Prabhu K, Raj S, Rani S. Antimicrobial and hemolytic activity of fish epidermal mucus Cynoglossus arel and Arius caelatus. Asian Pac J Trop Med 2011; 305-9.

[28] Kuppulakshmi C, Prakash M, Gunasekaran G, Manimegalai G, Sarojini S. Antibacterial properties of fish mucus from Channa punctatus and Cirrhinus mrigala. Eur Rev Med Pharmacol Sci 2008; $12: 149-53$.

[29] Uthayakumar V, Ramasubramanian V, Senthilkumar D, Brindha PV, Harikrishnan R. Biochemical characterization, antimicrobial and hemolytic studies on skin mucus of fresh water spiny eel Mastacembelus armatus. Asian Pac J Trop Biomed 2012; S863-9.

[30] Hellio C, Bremer G, Pons AM, Le Gal Y, Bour Gougnon N. Inhibition of the development of microorganisms (bacteria and fungi) by extracts of marine algae from Brittany (France). Appl Microbiol Biotech 2000; 54: 543-9. 